\title{
Streamlining the Process of Communicating and Recording the Gender of the Newborn Child in the Labor Room
}

\author{
${ }^{1}$ Deepti Sahran, ${ }^{2}$ Vijay K Tadia, ${ }^{3}$ SK Arya
}

\section{ABSTRACT}

Purpose: The article tries to streamline the process of communicating and recording the gender of newborn in the birth certificate in the labor room.

Design: Descriptive.

Materials and methods: Redesigning of the process of recording gender in hospital information system (HIS) module/ e-birth module using process mapping and feedback from stakeholders.

Results: There were instances of discrepancy in verbally communicating the gender of newborn soon after the birth and the gender being recorded in the birth certificate issued in the labor room. Soon after these instances were reported, the process was examined and redesigned. After implementation of the redesigned process, follow-up was done and it was noted that there had been no further instances of discrepancies in communication of sex of the newborn child and recording of gender in the birth certificate. However, to institutionalize the change and to prevent any further mishaps in future and to eliminate chances of all possible human errors, it was decided that the whole process will be retested and all possible loopholes will be identified, with the aim to create a process which achieves the objective of elimination of all possible human errors (mistakeproofing). Initially, the process mapping was done. Later, the new process of recording birth-related information including gender was codified and implemented. The follow-up was again done post this intervention. It was found that systemic changes had streamlined the process. This had resulted not only in right gender recording and elimination of possibility of any errors, but also in reduction of number of visits by patients to labor room to get birth certificate.

Conclusion: Investigation of errors and redesigning of processes help in rooting out various defects in the system. Therefore, all the acts of omission/commission resulting in undesirable outcomes should be used as opportunities for overall improvement rather than to find fault of erring employees. As in this case, the overall approach was to improve the existing system leading to elimination of chances of any mistake and streamlining operations leading to desired outcomes.

Keywords: Electronic module, Quality improvement, Root cause.

\footnotetext{
${ }^{1,2}$ Resident Administrator, ${ }^{3}$ Professor

${ }^{1-3}$ Department of Hospital Administration, All India Institute of Medical Sciences, New Delhi, India
}

Corresponding Author: Vijay K Tadia, Resident Administrator Department of Hospital Administration, All India Institute of Medical Sciences, New Delhi, India, e-mail: vijay@vijaytadia.org
How to cite this article: Sahran D, Tadia VK, Arya SK. Streamlining the Process of Communicating and Recording the Gender of the Newborn Child in the Labor Room. Int J Res Foundation Hosp Healthc Adm 2016;4(2):66-69.

\section{Source of support: Nil}

Conflict of interest: None

\section{INTRODUCTION}

Quality improvement (QI) consists of systematic and continuous actions that lead to measurable improvement in health care services and the health status of targeted patient groups. To make improvements, an organization needs to understand its own delivery system and key processes. The key concept behind the QI approach is that both resources (inputs) and activities carried out (processes) are addressed together to ensure or improve quality of care (outputs/outcomes). ${ }^{1}$

Process mapping is a tool commonly used by an organization to better understand the ongoing processes within the system. A process map provides a visual diagram of a sequence of events that may result in a particular outcome. This helps in identifying bottlenecks and potential opportunities for improvement. The process mapping tool can thus be used to evaluate and redesign a current process. ${ }^{1}$

\section{BACKGROUND}

Head of the Department of Pediatrics had written a letter to Head of the Department of Obstetrics and Gynecology informing about wrong recording of gender of newborn by junior resident (JR), Obstetrics and Gynecology, in the e-birth record in the month of August 2015. This lapse came into notice when the ward sister in private ward had refused to accept the female baby as on face sheet of case file where the newborn sex had been recorded as male instead of female. On inquiry, it was brought to notice that this baby sex was wrongly entered as male by JR, Obstetrics and Gynecology in the gender column in e-birth certificate module in HIS in labor room. Therefore, face sheet of case file of newborn had shown this baby as male, instead of female.

Medical Superintendent decided to inquire into the matter so that remedial measure could be initiated. Discussions were held with all stakeholders to review 
the existing practices and identify immediate remedial measures to ensure that such instances do not happen in future. It was decided to follow QI approach in this case.

This group discussed the matter to find out the root cause of the problem. As it was a matter of grave legal importance and to prevent any such incidence in future, the whole process of e-birth record was examined and intervention was carried out in a phased manner.

A number of QI models are presently in use and five are highlighted here. Two of the models, Care Model and Lean Model, provide a framework to improve patient care, whereas the other three models, Model for Improvement, Focus Analyze Develop Execute and Evaluate (FADE), and Six Sigma, focus on processes that monitor the results of measures. There are four broad steps to the FADE QI model: Focus-define process to be improved, Analyze-collect and analyze data, Develop-develop action plans for improvement, Execute-implement the action plans, and Evaluate-measure and monitor the system to ensure success. ${ }^{1}$

In the present case using FADE model, the errors were identified and analyzed in a step-wise manner. A plan was then developed for removal of the errors that involved redesigning of the Information Technology (IT) processes and existing reporting practices. Progress was monitored for the next 6 months and it was noticed that no case was reported where there was any discrepancy in communicating the gender of newborn after redesigning the process of IT in e-birth module.

\section{Previous Practices}

Previously, only pediatric resident used to identify the sex of the newborn and inform the sex of the newborn to the mother/relative and then used to fill the admission slip of the newborn and neonatal case sheet. The obstetrics and gynecology resident used to fill all the details of the newborn in the e-birth form and then after putting their initials used to send the e-birth form to the admission counter for admission of the newborn.

\section{Electronic Birth Module}

The documentation of birth is a universal practice widely practiced throughout human civilization. The child shall have the right, from birth, to a name and the right to acquire a nationality. So, the importance of a birth certificate for a child is immense.

According to the Registration of Births and Deaths Act, 1969 (Act no. 18 of 1969), every birth and death has to be notified. Every birth or death is to be reported and registered within 21 days at the place of its occurrence in the prescribed reporting forms. The Birth and Death Certificates in Delhi are issued by the Local Bodies namely MCD, NDMC, Delhi Cantonment Board within 7 days from the date of receipt of application from the applicant, provided the birth/death has already been registered. This procedure is being followed as per the guidelines of Registration of Births \& Deaths Act 1969 (RBD Act) and Delhi State Rules for Registration of Births \& Deaths 1999. The MCD introduced computerization of births and deaths on 19 February, 2003. The MCD had introduced a scheme called On Line Institutional Registration where nearly 400 hospitals have been empanelled and issued user id and password for uploading registration data. This software has been appreciated at national and international level and is referred as MCD model. ${ }^{2}$

\section{Background}

In December 2014, as a part of digitalization, a web-based application "E-BIRTH MODULE" was introduced in All India Institute of Medical Sciences, New Delhi, India.

\section{PROBLEM IDENTIFICATION AND QI TOOL IMPLEMENTATION}

In the instant case regarding miscommunication of gender of the newborn child, the following problems were identified during the initial meeting held with the various stakeholders (as per FADE Model of Quality Initiative):

The ongoing practice was that only Pediatric resident used to identify the sex of the newborn and inform the sex of the newborn to the mother/relative. Pediatric resident used to fill the admission slip of the newborn and neonatal case sheet thereafter. The Obstetrics and Gynecology resident used to fill all the details of the newborn in the e-birth form, and send the e-birth form as part of procedure for admission of the newborn.

With this process, the following problems were being faced by the residents of Department of Obstetrics and Gynecology:

- While filling the e-birth form, there were various entries in the e-birth form which did not have any options in the scroll down menu and this sometimes led to mistakes.

- While filling the e-birth form, male sex and Hindu religion were being shown as default settings on the form and sometimes on scrolling down, the selection of female sex got changed automatically to male. Time of admission and date of delivery were being shown as zero in default settings and APGAR score was being shown as 1 in default settings.

- Address on the birth form was self-populated and was the same as on the face sheet of the admission paper. Some patients used to come back searching for the same resident who had signed earlier on the birth form with a request to make changes in the 
address after the documentation had been completed. To accommodate such requirements, the birth form printout used to be taken out and the concerned resident (who had signed the certificate earlier) signed the form with correct address. This forced the newborn's family members to make one or more visit to hospital to get necessary changes made in address, which was a major cause of inconvenience to the patients.

- The computerized form had few spelling mistakes which needed correction.

\section{Quality Improvement Remedial Measures and Action taken}

Initially, the following remedial measures were undertaken immediately by obstetrics and gynecology residents to prevent the above-mentioned problems:

- On the directions of the head of department, obstetrics and gynecology, all the obstetrics and gynecology residents had started declaring the sex of the newborn child to the mother or the relatives in addition to the Pediatrics resident.

- In addition to this, the birth register and the live birth form were being filled and signed by the resident conducting the delivery in legible handwriting and a senior resident (SR) countersigned it. But still, some residents were not writing their names under the signature and the relative's signature was also being taken without any mention of his/her relationship with the mother or the name of the relative was not being mentioned on the form.

After the above-mentioned problems were identified by coordinating various meetings with the stakeholders, another meeting was arranged by the Department of Hospital Administration with the Computer Facility to rectify the problem and to incorporate necessary changes required in the e-birth module.

The initial changes incorporated in the e-birth form were as follows:

- The computer program was modified to add a counter signature block column in the existing form where the name of the SR assisting the procedure could be entered in the system and an additional separate column was added at the end of the form, where a note stating that "The above-mentioned particular are correct in my knowledge and no correction will be made in future" and below this statement the father/ mother/relative name was written with signature block.

- The computer program was modified to show "select" as default option for all the below mentioned situations and then on scrolling/drop down relevant options can then be selected as depicted in Table 1:
Table 1: List of changes carried out in the computer program

\begin{tabular}{|c|c|c|}
\hline $\begin{array}{l}\text { SI. } \\
\text { no. }\end{array}$ & $\begin{array}{l}\text { Default settings before } \\
\text { intervention }\end{array}$ & $\begin{array}{l}\text { Default settings after } \\
\text { intervention }\end{array}$ \\
\hline 1 & Sex-female & Sex-select \\
\hline 2 & Religion—hindu & Religion—select \\
\hline 3 & Methods of delivery—natural & $\begin{array}{l}\text { Methods of delivery- } \\
\text { select }\end{array}$ \\
\hline 4 & $\begin{array}{l}\text { Nature of labor- } \\
\text { spontaneous }\end{array}$ & Nature of labor-select \\
\hline 5 & $\begin{array}{l}\text { Rupture of membranes- } \\
\text { artificial rupture of } \\
\text { membranes (ARM) }\end{array}$ & $\begin{array}{l}\text { Rupture of membranes- } \\
\text { select }\end{array}$ \\
\hline 6 & $\begin{array}{l}\text { Induced vaginal delivery- } \\
\text { successful }\end{array}$ & $\begin{array}{l}\text { Induced vaginal delivery- } \\
\text { select }\end{array}$ \\
\hline 7 & $\begin{array}{l}\text { Trial of labor before lower } \\
\text { segment cesarean section } \\
\text { (LSCS)_yes }\end{array}$ & $\begin{array}{l}\text { Trial of labor before } \\
\text { LSCS—select }\end{array}$ \\
\hline 8 & $\begin{array}{l}\text { Gestational age- } \\
\text { appropriate-for-dates (AFD) }\end{array}$ & Gestational age—select \\
\hline 9 & $\begin{array}{l}\text { Live birth-live born and } \\
\text { fresh }\end{array}$ & Live birth—select \\
\hline 10 & Time of admission—zero & Time of admission—select \\
\hline 11 & Date of delivery—zero & Date of delivery—select \\
\hline 12 & APGAR score-1 & APGAR score-select \\
\hline
\end{tabular}

- In addition, a few medical terminology spellings were also corrected in the e-birth form and were incorporated in the computer software.

- At each step, whenever changes were incorporated in e-birth module by coordinating with the programmer, the changes were then shown to User Department and the Medical Record Department for their feedback. These proposed changes were then made after seeking concurrence of all the stakeholders. These changes made the software more user-friendly.

- All these changes that were incorporated in the e-birth form were again shown to the User Department and then implemented after their concurrence. The changes incorporated in the e-birth form made e-birth module more user-friendly and robust with minimum chances of recurrence of the incidence of wrong entry of sex. These measures helped in streamlining the process and preventing errors of communicating sex of newborn as well as recording of the correct address on the birth certificate.

- There was a need to integrate the e-hospital by the nurse informatics specialists (NIS) with the e-birth module and User Department had to put up the requirements to both the programmer and NIS for smooth functioning. During this exercise, it became evident that all the stakeholders have been working in silos and there is a need for someone to be a connecting links between them to facilitate and coordinate various activities of the user department and the computer facility. The integration of both hardware and software is required and a team approach is a 
must to make the system work in a robust manner and to make it foolproof without any errors.

- This was achieved by facilitating and coordinating various meetings, with the programmer in Computer facility and the User Department. This led to streamlining of the process with modification in the e-birth module.

- On follow-up, it was noted that there had been no further instances of miscommunication of sex of the newborn child after incorporation of the changes in the e-birth module.

\section{POST INTERVENTION IMPACT}

One year after the implementation of changes incorporated in the e-birth module, a post intervention study was carried out, which showed that there was not even single instance of discrepancy in verbally communicating the gender of newborn soon after the birth and the gender being recorded in the birth certificate. This positive result was possible through a small quality initiative implemented through a team approach.

\section{CONCLUSION}

Quality improvement consists of a set of systematic processes and actions that can lead to a measurable improvement in health care services. An organization needs to understand its own delivery system and key processes to make effective changes and deliver quality care to its dependent clientele. Improvement requires change, but not every change is an improvement. The model for improvement is a strategy to systematically and effectively manage change, which stemmed from the work of William Edwards Deming, also known as the founder of continuous QI. A QI program is not intended for attributing blame, but rather for creating systems that prevent errors and improve health outcomes. The QI activities are designed to improve how things work. While the process of finding where the system can be refined or new ways to do things can be challenging, the process can also be rewarding. These QI activities provide an organization with opportunities to "think outside the box" and promote creativity and innovation. ${ }^{1}$

Similar to FADE, root cause analysis (RCA) is a promising approach with considerable face validity as a way of producing learning from things that have gone wrong. A practice which has been followed worldwide for investigation of serious incidents is RCA. ${ }^{3}$

Incident investigation clearly will continue to play an important role in making health care safer, but it must first get better at doing what it does. ${ }^{3}$
Quality improvement is basically a team process and under the right conditions and right composition, a team harnesses the knowledge, skills, experience, and perspectives of different individuals within the team to make lasting improvements. In an organization that seeks to improve patient care services, a team effort by the QI team helps the organization to achieve significant and lasting improvements. In a team, every member brings a unique perspective to the process, i.e., how things work, what happens when changes are made, and how to sustain improvements during daily work, and every member has a responsibility to be active and contributing member of the team. Positive interactions among departments that work together to create a dynamic mechanism for continuously improving processes and outcomes of health care services ensure that quality patient care services are achieved. Successful implementation of a QI program begins with an honest and objective assessment of an organization's current culture, and its commitment to improving the quality of its care and services. ${ }^{1}$

Investigation of such errors helps in rooting out various defects in the system and should be seen as an exercise in overall improvement rather than a faultfinding mission. As in this case, the overall approach was to improve the existing system so as to reduce the chances of a mistake recurring (mistake-proofing). All such exercises have to be collaborative efforts between the users and the hospital administration with the overall aim of improvement of patient care.

\section{ACKNOWLEDGMENTS}

Author would like to thank Dr K Aparna Sharma, Associate Professor, Department of Obstetrics and Gynecology, All India Institute of Medical Sciences, New Delhi, for her intellectual and critical input, and Mrs Atasi Behera, Software Programmer for technical inputs.

\section{REFERENCES}

1. HRSA. Quality Improvement. In: US Department of Health and Human Services Health Resources and Services Administration [Internet]. 2011. p. 19. Available from: http://www.hrsa. gov/quality/toolbox/508pdfs/qualityimprovement.pdf dated 10 August 2016 at $1135 \mathrm{hrs}$.

2. Registration and issue of birth and death certificate [Internet]. Available from: http://111.93.47.72/csbedmc/rbd/circulerslist. php\# dated 02 August 2016 at 1410hrs.

3. Peerally MF, Carr S, Waring J, Woods MD. The problem with root cause analysis. BMJ Qual Saf. 2016;(0):1-6 dated 09 July 2016 at $1058 \mathrm{hrs}$. 